\title{
Methylation-wide human study identified age and BMI-inde- pendent association of differentially methylated regions and leukocyte telomere length
}

\author{
Carolina F Nicoletti ${ }^{1}$, Natalia Y Noronha ${ }^{2}$, Marcela A S Pinhel ${ }^{3}$ and Carla B Nonino ${ }^{4 *}$ \\ 1 Laboratory of Nutrigenomics Studies, Department of Health Science, Ribeirão Preto Medical School, Uni- \\ versity of Sao Paulo, Ribeirão Preto, Brazil.; carol_nicolettif@yahoo.com.br \\ 2 Department of Internal Medicine, Ribeirão Preto Medical School, University of Sao Paulo, Ribeirão Preto, \\ Brazil.; natty.yumi@gmail.com \\ 3 Laboratory of Studies in Biochemistry and Molecular Biology, Department of Molecular Biology, São José \\ do Rio Preto Medical School, Brazil and Laboratory of Nutrigenomics Studies, Department of Health Sci- \\ ence, Ribeirão Preto Medical School, University of Sao Paulo, Ribeirão Preto, Brazil.; marcelapinhel@ya- \\ hoo.com.br. \\ 4 Laboratory of Nutrigenomics Studies, Department of Health Science, Ribeirão Preto Medical School, Uni- \\ versity of Sao Paulo, Ribeirão Preto, Brazil.; carla@fmrp.usp.br \\ * Correspondence: carla@fmrp.usp.br
}

\begin{abstract}
Background: Telomere length (TL) shortening process is associated with several known environment and individual determinants. DNA methylation is the most studied epigenetic process and may be associated with TL. We investigated the associations between DNA methylation and TL in peripheral blood. Methods: Methylation wide association study was conducted in 47 women (37.1 \pm 8.8 years) with different nutritional status. Association between TL and DNA methylation levels were explored by univariate and multiple linear regression models, corrected by age and Body Mass Index. Corrections for multiple comparisons by Benjamini-Hochberg test was also performed. WEBGestalt was used to identify pathways that are responsible for regulating TL. Results: We found negative correlations between TL and BMI $(r=-0.641 ; \mathrm{p}=0.001)$, abdominal circumference $(\mathrm{r}=$ $0.622 ; \mathrm{p}=0.001)$ and fat mass $(\mathrm{r}=-0.656 ; \mathrm{p}=0.001)$. $44 \mathrm{CpGs}$ sites were associated with $\mathrm{TL}$, independent of age and BMI. The most of these sites were negatively correlated with TL. For the 7 remained sites, DNA hypomethylation were associated with shorter TL. These CpGs were related to nine different pathways, including thermogenesis, cancer, glutamatergic and serotonergic synapse. Conclusion: There is an epigenetic contribution in TL, independent of nutritional status and age. Genes related to TL are involved in important metabolic pathways.
\end{abstract}

Keywords: telomere length; DNA methylation; DNA microarray

\section{Introduction}

Telomeres are DNA nucleoprotein structures located at the end of eukaryotic chromosomes consisting of hundreds to thousands tandem repeats of TTAGGG [1,2], that play an important role in preventing chromosomes from erosion and end-to-end fusion, and thereby maintaining chromosome's integrity [1]. Telomeres are shortened at each cell division and this mechanism decrease chromosomal stability. Also, telomere erosion believed to be accelerated by oxidative stress and inflammation [3,5], which increases risks for chronic diseases, cancer, cardiovascular disease, and overall mortality [6]. In line of this, there is a significant inter-individual variation in telomere length (TL) shortening rates throughout life [7]. TL shortening process is associated with several known environment and individual inherent determinants, including smoking [8], excessive alcohol consumption [9], diet [10], physical activity [11], obesity [12] and chronic life stress [13]. In 
addition, TL is also influenced by genetic variations. Recent genome-wide association studies (GWAS) have identified several polymorphisms associated with TL $[14,15]$. Furthermore, recent studies in epigenetic research have demonstrated the contribution of DNA methylation levels in TL $[16,19]$. DNA methylation, one of the main mechanisms of epigenetic modification, consists in addiction of cytosine residues of cytosine-phosphateguanine dinucleotides (CpGs), which plays an important role in gene expression control $[20,21]$. Importantly, both TL and DNA methylation process are involved in aging and disease development and global DNA hypomethylation was previously associated with TL in adults $[16,22]$. Despite the evidence, the epigenetic basis of TL remains largely unknown. Therefore, we carried out this cross-sectional study to explore the DNA methylation profile in relationship with marker of TL in women. The present study, for the first time, tested the hypothesis that TL would be associated with DNA methylation level, independent of nutritional status and age. First, we performed Human Methylation $450 \mathrm{mi}-$ croarray analysis and measured TL in DNA from women patients. Also, we investigated the associations between methylation at CpG sites and TL in peripheral blood DNA.

\section{Results}

2.1 Phenotypic Characteristics and Telomere length measurements

Phenotypic characteristics and TL of study participants are described in Table 1. We observed that $48.9 \%$ of women had overweight or obesity. Also, we found negative correlations between TL and BMI $(r=-0.641 ; p=0.001)$, abdominal circumference $(r=-0.622 ; p=$ $0.001)$ and fat mass $(r=-0.656 ; p=0.001)$.

Table 1. Phenotypic and TL characteristics of study participants $(n=47)$

\begin{tabular}{lc}
\hline Age (years) & $37.1 \pm 8.8$ \\
Weight $(\mathrm{kg})$ & $86.5 \pm 26.4$ \\
BMI $\left(\mathrm{kg} / \mathrm{m}^{2}\right)$ & $39.9 \pm 10.7$ \\
Abdominal circumference $(\mathrm{cm})$ & $100.6 \pm 23$ \\
Fat free mass $(\mathrm{kg})$ & $51.9 \pm 10$ \\
Fat mass $(\mathrm{kg})$ & $33.3 \pm 16.7$ \\
TL $(\mathrm{T} / \mathrm{S}$ ratio) & $0.93 \pm 0.11$ \\
\hline
\end{tabular}

BMI: body mass index. TL: telomere length.

\subsection{Epigenome wide DNA methylation analysis}

After normalization by quality control, the experiment ends up with 410.586 valid probes. After linear regression, $176 \mathrm{CpG}$ sites (located in 154 unique genes) were associated with $T L$ at the conventional pvalue $<0.05$ and remained associated after adjustment for multiple comparisons (FDR corrected pvalue $<0.05$ ) (Supplementary Table).

However, the identified CpGs did not remained associated with TL after adjustment for BMI and age. Thus, we identified 44 sites within 39 different genes that were associated with TL in whole blood DNA, independent of age and BMI (Table 2). The most of these sites were in promoter region (68.1\%), island (52.3\%) and in chromosome $6(18.2 \%)$. 
Table 2. $44 \mathrm{CpGs}$ sites related to telomere length after adjustment for BMI and age

Chromosome

\begin{tabular}{|c|c|c|c|c|c|}
\hline CpG & Chromosome & MapInfo & Gene symbol & Gene Region & Region \\
\hline \multicolumn{6}{|c|}{ Negative association } \\
\hline cg05445839 & & 27023088 & ARID1A & 1stExon & Island \\
\hline $\operatorname{cg} 03421104$ & & 5793847 & & & S_Shore \\
\hline $\operatorname{cg} 18973238$ & 1 & 64169293 & & & \\
\hline $\operatorname{cg} 10499166$ & & 23345815 & KDM1A & TSS200 & Island \\
\hline cg07283098 & 3 & 134514086 & EPHB1 & TSS200 & Island \\
\hline $\operatorname{cg} 15693898$ & & 183602556 & PARL & 1stExon & Island \\
\hline $\operatorname{cg} 16009381$ & 5 & 173043599 & BOD1 & 5'UTR & Island \\
\hline $\operatorname{cg} 01735621$ & & 74162051 & C6orf150 & TSS200 & Island \\
\hline cg00309106 & & 31865663 & EHMT2 & TSS200 & S_Shore \\
\hline cg01702338 & & 32812571 & PSMB8 & 5'UTR & S_Shore \\
\hline cg21128553 & & 3163406 & & & Island \\
\hline cg25760338 & & 52860082 & GSTA4 & 5'UTR;1stExon & S_Shore \\
\hline $\operatorname{cg} 24203851$ & 6 & 111136481 & CDK19 & TSS200 & Island \\
\hline $\operatorname{cg} 26289450$ & & 32158233 & PBX2 & TSS1500 & \\
\hline cg22592140 & 7 & 130132419 & MEST & 5'UTR & Island \\
\hline cg14298577 & & 100272703 & GNB2 & 5'UTR & Island \\
\hline $\operatorname{cg} 27338396$ & & 26241120 & BNIP3L & Body & S_Shore \\
\hline cg13551243 & & 146052742 & ZNF7 & TSS200 & Island \\
\hline $\operatorname{cg} 16274098$ & & 92053265 & TMEM55A & TSS200 & \\
\hline $\operatorname{cg} 23731089$ & 8 & 141599208 & $\mathrm{EIF} 2 \mathrm{C} 2$ & Body & \\
\hline cg08446255 & & 26434378 & DPYSL2 & TSS1500 & Island \\
\hline $\operatorname{cg} 15573846$ & 11 & 126152723 & TIRAP & TSS1500 & Island \\
\hline $\operatorname{cg} 23766360$ & 12 & 6193688 & VWF & Body & \\
\hline cg02101876 & 13 & 40765110 & & & \\
\hline cg06488135 & 14 & 94641122 & PPP4R4 & Body & Island \\
\hline cg25198579 & & 67358136 & SMAD3 & TSS200 & Island \\
\hline cg08370718 & & 49913307 & DTWD1;C15orf33 & 1stExon & Island \\
\hline cg00036440 & 15 & 3507875 & NAT15 & 5'UTR & Island \\
\hline cg00239353 & & 3115133 & IL32 & TSS1500 & \\
\hline $\operatorname{cg} 08676730$ & 17 & 53828263 & РСТP & TSS200 & N_Shore \\
\hline cg13893634 & & 48229117 & PPP1R9B & TSS1500 & S_Shore \\
\hline cg04349727 & 19 & 51457389 & KLK5 & TSS1500 & \\
\hline cg17064051 & & 3713345 & HSPA12B & TSS200 & Island \\
\hline $\operatorname{cg} 16871527$ & 20 & 20693360 & RALGAPA2 & TSS200 & Island \\
\hline $\operatorname{cg} 14263118$ & & 57463787 & GNAS & 3'UTR & Island \\
\hline cg12818493 & 21 & 44527599 & $\mathrm{U} 2 \mathrm{AF} 1$ & 5'UTR & Island \\
\hline $\operatorname{cg} 04454272$ & 22 & 31795531 & DRG1 & TSS200 & Island \\
\hline \multicolumn{6}{|c|}{ Positive association } \\
\hline cg01919885 & 4 & 3365330 & RGS12 & Body & Island \\
\hline
\end{tabular}




\begin{tabular}{lccccc}
\hline cg13941682 & 702545 & PCGF3 & 5'UTR & S_Shelf \\
cg03660010 & & SLAIN2 & TSS1500 & N_Shore \\
cg17745803 & 6 & 29631321 & Body & \\
$\operatorname{cg} 19916067$ & 8 & 143389706 & TSNARE1 & Body \\
cg12152384 & 12 & 47164566 & Body & \\
$\operatorname{cg} 00989002$ & 16 & 52225569 & & & \\
\hline
\end{tabular}

For all 44 identified CpGs, 84.1\% (37 CpGs) were negatively correlated with TL. For these sites, lower DNA methylation levels were associated with bigger TL. On other hand, for remained 7 CpGs sites, DNA hypomethylation were associated with shorter TL (Table 2). Enrichment analysis showed that these CpGs were related to nine different pathways (Table 3), including thermogenesis, pathways in cancer, glutamatergic and serotonergic synapse.

Table 3. Enrichment results for CpGs sites related to telomere length

\begin{tabular}{lcc}
\hline Gene set & Pathway & Size \\
\hline hsa04926 & Relaxin signaling pathway & 130 \\
hsa05225 & Hepatocellular carcinoma & 168 \\
hsa04714 & Thermogenesis & 229 \\
hsa05032 & Morphine addiction & 91 \\
hsa04713 & Circadian entraiment & 96 \\
hsa05200 & Pathways in cancer & 526 \\
hsa04724 & Glutamatergic synapse & 114 \\
hsa04726 & Serotonergic synapse & 115 \\
hsa04611 & Platelet activation & 123 \\
\hline
\end{tabular}

\section{Discussion}

As our mainly result, we identified multiple CpG sites in which DNA methylation levels were associated with leukocyte TL independent of nutritional status and age. For the majority of the identified CpGs sites, lower levels of DNA methylation were associated with bigger TL (negative association). These associated genes were involved in different metabolic pathways, such as thermogenesis, circadian entrainment pathway and cancer pathways. In the same way, Buxton et al. 2014 [16] identified 65 CpG sites at which methylation levels associated with leukocyte $\mathrm{TL}$, of these sites, $78 \%$ were positively associated. Also, authors evaluating global DNA methylation evidenced that Alu and/or LINE-1 DNA hypomethylation were associated with shorter TL [25]. We evidenced that, when adjusted for age and BMI and age, the number of CpG sites that remained associated with TL decreased. This is the first evidence of the relation between these CpG sites and TL, however the reason of this association remained unknown. We consider two hypotheses: the loci in which these $\mathrm{CpG}$ sites are capable induce changes in telomere length or metabolic pathways, which the genes are associated is capable to affect telomere length. It is already known that epigenetic changes near telomeres could influence its length [16; 26]. Telomeric regions do not contain $\mathrm{CpG}$ substrates that are susceptible to methylation by DNA methyltransferases (DNMTs), but subtelomeric region has a high number of CpG sites, which can be methylated [27]. However, the $44 \mathrm{CpGs}$ identified in the present analysis were not in subtelomeric regions, and thus, the present hypothesis cannot be confirmed. 
An important pathway related to TL in the preset study was the circadian entrainment pathway. Previously results evidenced circadian rhythm as a mechanism underlying telomere and telomerase activity [28]. The authors suggest that this association has essential clinical impacts, which a possible link between circadian desynchrony and telomere dysfunction [28]. Moreover, pathways in cancer appear as the major pathway related to TL in our results. According to some authors, in cancer development context, telomere shortening may have antagonistic outcomes that involve genome instability and prevention of cancer progression $[29,30]$. Interestingly, there is an already known association between the both above pathway. The circadian clock seems to have an important role in multiple physiological processes, homeostasis and, for this reason may control several cancer hallmarks [31]. Despite many evidence about the contribution of different metabolic strategies for energy homeostasis on TL (i.g green tea supplementation; diet; endurance, interval, and resistance training) [12; 32,33], according to our knowledge, this is the first study showing the direct association between thermogenesis and TL. Here, different explanations may be point out for this association. First, improvement of oxidative stress and inflammation have been associated with better measurements of TL $[34,35]$. On other hand, it is already known that phosphate is an essential mineral for body energy generation process and recent association has been made between higher phosphate levels and longer TL [36]. Other pathways evidenced in the present study have being described for the first time. The molecular mechanism that relaxin signaling pathway, platelet activation and glutamatergic/ serotonergic synapse pathway is associated to TL need to be further investigate. Like epigenetic clocks, we expect that DNA methylation level may become a useful biomarker for human aging in interventional studies. Considering that epigenetic biomarkers are still in the nascent stage, we will highlight the importance of future prospective study to confirm DNA methylation level as epigenetic biomarkers of TL and possible human disease. Strengths of our study include the wide analysis of DNA methylation by array technology. Limitations include the small sample size and the age range adopted in the inclusion criteria. However, despite the number of included participants, important associations were found.

\section{Materials and Methods}

\section{Study design and subjects}

We performed our methylation wide association study with 47 women (aged between 20 and 60 years old) from an ethnic mixed population, on different nutritional status (according to body mass index - BMI). We did not included patients a history of metabolic diseases such as Cushing syndrome hypo or hyperthyroidism and those in use of antiobesity medications or hormone therapy. Also, men were excluded to avoid the possible biases due to the hormonal influences. For this cross-over study, patients were evaluated only once. Data collection included anthropometrics (weight, height, abdominal circumference, and BMI) and body composition (fat mass and fat free mass) measurements and blood collection for genetic analysis.

\section{DNA extraction}

Genomic DNA was extracted from leukocytes using the Master Pure kit (Epicenter, Madison, WI). DNA fragmentation or RNA contamination was analyzed by $1 \%$ agarose gel electrophoresis. All samples were stored at $-80^{\circ} \mathrm{C}$ until analyzed.

Measurements of leukocyte telomere length

Analysis for leukocyte telomere length were performed using the method developed by Cawthon et al. [23], with specific modifications [12]. Briefly, Real-time PCR was performed using a 7500 Fast Real Time PCR System (Applied Biosystems). Assay method 
was optimized for use of both telomere (T) and single copy gene (S) amplifications on the same 96-well plate, with reference standard DNA samples on each plate. Analyses were performed in triplicate PCR reactions. Amplification primers for telomeres included TelF: 5'-GGTTTTTGAGGGTGAGGGTGAGGGTGAGGGTGAGGGT-3' and TelR: 5'TCCCGACTATCCCTATCCCTATCCCTATCCCTATCCCTA-3', and for 36B4u: 5'CCCATTCTATCATCAACGGGTACAA-3' and 36B4d: 5'-CAGCAAGTGGGAAGGTGTAATCC-3'. The relative quantification of TL was determined using the telomere to single copy gene ratio $(\mathrm{T} / \mathrm{S})[2-(\Delta \mathrm{Ct}$ (telomere $)-\Delta \mathrm{Ct}$ (Single copy gene $)=2-\Delta \Delta \mathrm{Ct}]$, following the parameters of Scheinberg et al, 2010 [24]. For $2-\Delta \Delta \mathrm{Ct}$ calculation, each sample was normalized to the average T/S ratio of a reference sample, using the standard curve and validation sample as reference.

Methylation assay

Genomic DNA was bisulfate converted immediately before methylation analysis using EZ-96 DNA Methylation Kit (Zymo Research Corporation, Irvine, CA). Methylation chips manufactured by Illumina (Infinium Human Methylation 450 array, Illumina, San Diego, CA) were used for generating methylation data. Beadchips were scanned with the Illumina HiScanSQ system, and image intensities were extracted with the Genome Studio (2011.1) Methylation Module (v1.8.5). Blood samples from each subject were hybridized to the same physical chip to minimize biases. The methylation level was expressed as a beta $(\beta)$ value that was calculated as the intensity of the methylated channel divided by the total intensity $[\beta=\operatorname{Max}($ SignalB , 0) / (Max (SignalA, 0) + Max (SignalB, 0) +100]. A threshold for the significant $\mathrm{CpG}$ sites based on $\triangle$ beta with a minimum value of $5 \%$ (value greater than 0.05 or less than -0.05 ) and $p$ value $<0.001$ was applied.

\section{Statistical analysis}

Descriptive statistics consisted of mean and standard deviation (SD) values. Shapiro-Wilk test was used to verify the data normality. t-test for independent samples was used for phenotypic variables and TL comparisons between obese and normal weight women. Association between TL and DNA methylation levels were explored by univariate and multiple linear regression models, in which outcome measurement was TL and confounding variables included age and BMI. Corrections for multiple comparisons by BenjaminiHochberg test was also performed.The significance level used for the tests was set at $\mathrm{p}<0.05$. All analyses were performed by using SPSS Statistics 21.0 (SPSS Inc.).

\section{Pathway Enrichment Analysis}

WEBGestalt (WEB-based GEne SeT AnaLysis Toolkit) was used to identify pathways that are responsible for regulating TL. For this, the list of genes associated with TL was submitted for statistical overrepresentation testing (Fisher's exact test) in KEGG (Kyoto Encyclopedia of Genes and Genomes). Pathways were considered over-represented where False Discovery Rate (FDR) $\mathrm{p}<0.05$.

\section{Conclusions}

The results of present study provide novel insights into the epigenetic contribution in telomere length, independent of nutritional status and age. Also, DNA methylation levels of genes involve in important metabolic pathways such as circadian, cancer and thermogenesis are associated with TL. 
Supplementary Materials: The following are available online at www.mdpi.com/xxx/s1, Figure S1: title, Table S1: title, Video S1: title.

Author Contributions: CFN and CBN contributed to the conception and design of the study. CFN, MASP and NYNW analyzed the data. CFN wrote the first draft of the manuscript. MASP and NYN aided with manuscript revisions. CBN provided guidance with manuscript improvements and statistical analysis. All authors read and approved the final manuscript.

Funding: This study was supported by São Paulo Research Foundation (FAPESP) (grants \#2016/05638-1 and \#2015/18669-0).

Institutional Review Board Statement: The study was conducted according to the guidelines of the Declaration of Helsinki, and approved by the Research Ethics Committee of the Clinical Hospital of Ribeirão Preto Medical School, University of São Paulo, SP, Brazil (CAAE: 62181816.3.0000.5440).

Informed Consent Statement: Informed consent was obtained from all subjects involved in the study.

Data Availability Statement: Raw data for the primary analyses are available upon request from the corresponding and senior author.

Acknowledgments: None to declare.

Conflicts of Interest: The authors declare no conflict of interest.

\section{References}

1. Blasco MA. Telomeres and human disease: Ageing, cancer andbeyond. Nat Rev Genet 2005, 6, 611-622.

2. Nordfjaill K, Svenson U, Norrback KF, Adolfsson R, Roos G. Large-scale parent-child comparison confirms a strong paternal influence on telomere length. Eur J Hum Genet 2010, 18, 385-89.

3. Coluzzi E, Colamartino M, Cozzi R, Leone S, Meneghini C,O'Callaghan N, Sgura A. Oxidative stress induces persis-tent telomeric DNA damage responsible for nuclear morphologychange in mammalian cells. PLoS One 2014, 9, e110963.

4. von Zglinicki, T. Oxidative stress shortens telomeres. TIBS 2002, 27, 339-344.

5. Kurz DJ, Decary S, Hong Y, Trivier E, Akhmedov A, Erusalimskyet JD. Chronic oxidative stress compromises telomere integrity and accelerates the onset of senescence in human endothelial cells. J Cell Sci 2004, 117, 24172426.

6. D'Mello MJJ, Ross SA, Briel M, Anand SA, Gerstein H, Paré G. Association Between Shortened Leukocyte Telomere Length and Cardiometabolic Outcomes. Circ Cardiovasc Genet 2015, 8, 82-90.

7. Farzaneh-Far R, Lin J, Epel E, Lapham K, Blackburn E, Whooley MA. Telomere Length Trajectory and Its Determinants in Persons with Coronary Artery Disease: Longitudinal Findings from the Heart and Soul Study. PLoS One 2010, 5, e8612.

8. Valdes AM, Andrew T, Gardner JP, Kimura M, Oelsner E, Cherkas LF, Aviv A, Spector TD. Obesity, cigarette smoking, and telomere length in women. Lancet 2005, 366, 662-664.

9. Strandberg TE, Strandberg AY, Saijonmaa O, Tilvis RS, Pitkälä KH, Fyhrquist F. Association between alcohol consumption in healthy midlife and telomere length in older men. The Helsinki Businessmen Study. Eur J Epidemiol 2012, 27, 815-822.

10. Zhu H, Bhagatwala J, Pollock NK, Parikh S, Gutin B, Stallmann-Jorgensen I, Thomas J, Harshfield GA, Dong Y. High sodium intake is associated with short leukocyte telomere length in overweight and obese adolescents. Int J Obes (Lond) 2015, 39, 1249-1253.

11. Zhu H, Wang X, Gutin B, Davis CL, Keeton D, Thomas J, Stallmann-Jorgensen I, Mooken G, Bundy V, Snieder $\mathrm{H}$, van der Harst P, Dong Y. Leukocyte telomere length in healthy Caucasian and African-American adolescents: relationships with race, sex, adiposity, adipokines, and physical activity. J Pediatr 2011, 158, 215-220. 
12. Nonino CB, Pinhanelli VC, Noronha NY, Quinhoneiro DCG, Pinhel MS, De Oliveira BAP, Marchini JS, Nicoletti CF. Green tea supplementation promotes leukocyte telomere length elongation in obese women. Nutr Hosp 2018, 35, 570-575.

13. Epel ES, Blackburn EH, Lin J, Dhabhar FS, Adler NE, Morrow JD, Cawthon RM. Accelerated telomere shortening in response to life stress. Proc Natl Acad Sci USA 2004, 101, 17312-17315.

14. Codd V, Nelson CP, Albrecht E, Mangino M, Deelen J, Buxton JL, Hottenga JJ, Fischer K, Esko T, Surakka I, Broer L, Nyholt DR, Mateo Leach I, Salo P, Hägg S, Matthews MK, Palmen J, Norata GD, O'Reilly PF, Saleheen D, Amin N, Balmforth AJ, Beekman M, de Boer RA, Böhringer S, Braund PS, Burton PR, de Craen AJ, Denniff M, Dong Y, Douroudis K, Dubinina E, Eriksson JG, Garlaschelli K, Guo D, Hartikainen AL, Henders AK, Houwing-Duistermaat JJ, Kananen L, Karssen LC, Kettunen J, Klopp N, Lagou V, van Leeuwen EM, Madden PA, Mägi R, Magnusson PK, Männistö S, McCarthy MI, Medland SE, Mihailov E, Montgomery GW, Oostra BA, Palotie A, Peters A, Pollard H, Pouta A, Prokopenko I, Ripatti S, Salomaa V, Suchiman HE, Valdes AM, Verweij N, Viñuela A, Wang X, Wichmann HE, Widen E, Willemsen G, Wright MJ, Xia K, Xiao X, van Veldhuisen DJ, Catapano AL, Tobin MD, Hall AS, Blakemore AI, van Gilst WH, Zhu H; CARDIoGRAM consortium, Erdmann J, Reilly MP, Kathiresan S, Schunkert H, Talmud PJ, Pedersen NL, Perola M, Ouwehand W, Kaprio J, Martin NG, van Duijn CM, Hovatta I, Gieger C, Metspalu A, Boomsma DI, Jarvelin MR, Slagboom PE, Thompson JR, Spector TD, van der Harst P, Samani NJ. Identification of seven loci affecting mean telomere length and their association with disease. Nat Genet 2013, 45, 422-427.

15. Prescott J, Kraft P, Chasman DI, Savage SA, Mirabello L, Berndt SI, Weissfeld JL, Han J, Hayes RB, Chanock SJ, Hunter DJ, De Vivo I. Genome-wide association study of relative telomere length. PLoS One 2011, 6, e19635.

16. Buxton JL, Suderman M, Pappas JJ, Borghol N, McArdle W, Blakemore AI, Hertzman C, Power C, Szyf M, Pembrey M. Human leukocyte telomere length is associated with DNA methylation levels in multiple subtelomeric and imprinted loci. Sci Rep 2014, 4, 4954.

17. Gao X, Zhang Y, Mons U, Brenner H. Leukocyte telomere length and epigenetic-based mortality risk score: associations with all-cause mortality among older adults. Epigenetics 2018, 13, 846-857.

18. Dong Y, Huang Y, Gutin B, Raed A, Dong Y, Zhu H. Associations between Global DNA Methylation and Telomere Length in Healthy Adolescents. Sci Rep 2017, 7, 4210.

19. Lu AT, Seeboth A, Tsai PC, Sun D, Quach A, Reiner AP, Kooperberg C, Ferrucci L, Hou L, Baccarelli AA, Li Y, Harris SE, Corley J, Taylor A, Deary IJ, Stewart JD, Whitsel EA, Assimes TL, Chen W, Li S, Mangino M, Bell JT, Wilson JG, Aviv A, Marioni RE, Raj K, Horvath S. DNA methylation-based estimator of telomere length. Aging (Albany NY) 2019, 11, 5895-5923.

20. Kadayifci FZ, Zheng S, Pan YX. Molecular Mechanisms Underlying the Link between Diet and DNA Methylation. Int J Mol Sci 2018, 19, 4055.

21. Siegfried Z, Simon I. DNA methylation and gene expression. Wiley Interdiscip Rev Syst Biol Med 2010, 2, 362-371.

22. Wong JYY, De Vivo I, Lin X, Grashow R, Cavallari J, Christiani DC. The Association Between Global DNA Methylation and Telomere Length in a Longitudinal Study of Boilermakers. Genet Epidemiol 2014, 38, 254-264.

23. Cawthon RM. Telomere measurement by quantitative PCR. Nucleic Acids Res. 2002, 30 , e47.

24. Scheinberg P, Cooper JN, Sloand EM, Wu CO, Calado RT, Young NS. Association of Telomere Length of Peripheral Blood Leukocytes With Hematopoietic Relapse, Malignant Transformation, and Survival in Severe Aplastic Anemia. JAMA 2010, 304, 1358-1364.

25. Udomsinprasert W, Kitkumthorn N, Mutirangura A, Chongsrisawat V, Poovorawan Y, Honsawek S. Global methylation, oxidative stress, and relative telomere length in biliary atresia patients. Sci Rep 2016, 6, 26969. 
26. Maeda T, Guan JZ, Koyanagi M, Higuchi Y, Makino N. Aging-Associated Alteration of Telomere Length and Subtelomeric Status in Female Patients With Parkinson's Disease. J Neurogenet 2012, 26, 245-251.

27. Steinert S, Shay JW, Wright WE. Modification of Subtelomeric DNA. Mol Cell Biol 2004, 24, 4571-4580.

28. Chen WD, Wen MS, Shie SS, Lo YL, Wo HT, Wang CC, Hsieh IC, Lee TH, Wang CY. The circadian rhythm controls telomeres and telomerase activity. Biochem Biophys Res Commun 2014, 451, 408-414.

29. Cherfils-Vicini J, Gilson E. Inhibiting TRF1 upstream signaling pathways to target telomeres in cancer cells. EMBO Mol Med 2019, 11, e10845.

30. Maciejowski J, de Lange T. Telomeres in cancer: tumour suppression and genome instability. Nat Rev Mol Cell Biol 2017, 18, 175-186.

31. Sulli G, Lam MTY, Panda S. Interplay between Circadian Clock and Cancer: New Frontiers for Cancer Treatment. Trends Cancer 2019, 5, 475-494.

32. Brandao CFC, Nonino CB, de Carvalho FG, Nicoletti CF, Noronha NY, San Martin R, de Freitas EC, JunqueiraFranco MVM, Marchini JS. The effects of short-term combined exercise training on telomere length in obese women: a prospective, interventional study. Sports Med Open 2020, 6, 5.

33. Werner CM, Hecksteden A, Morsch A, Zundler J, Wegmann M, Kratzsch J, Thiery J, Hohl M, Bittenbring JT, Neumann F, Böhm M, Meyer T, Laufs U. Differential effects of endurance, interval, and resistance training on telomerase activity and telomere length in a randomized, controlled study. Eur Heart J 2019, 40, 34-46.

34. Masi S, Salpea KD, Li K, Parkar M, Nibali L, Donos N, Patel K, Taddei S, Deanfield JE, D'Aiuto F, Humphries SE. Oxidative stress, chronic inflammation, and telomere length in patients with periodontitis. Free Radic Biol Med 2011, 50, 730-735.

35. Wolkowitz OM, Mellon SH, Epel ES, Lin J, Dhabhar FS, Su Y, Reus VI, Rosser R, Burke HM, Kupferman E, Compagnone M, Nelson JC, Blackburn EH. Leukocyte telomere length in major depression: correlations with chronicity, inflammation and oxidative stress--preliminary findings. PLoS One 2011, 6, e17837.

36. Yang ZY, Kao TW, Peng TC, Chen YY, Yang HF, Wu CJ, Chen WL. Examining the association between serum phosphate levels and leukocyte telomere length. Sci Rep 2020, 10, 5438. 